\title{
Low serum thyroxine concentrations and neural maturation in preterm infants
}

\author{
L S DE VRIES, J Z HECKMATT, J M BURRIN, L M S DUBOWITZ, AND V DUBOWITZ
}

Departments of Paediatrics and Neonatal Medicine and Medicine, Royal Postgraduate School, Hammersmith Hospital, London

SUMMARY The effect of hypothyroxinaemia on postnatal progression of the motor nerve conduction velocity was studied in 33 very low birthweight infants.

Serum concentrations of thyroid stimulating hormone, triiodothyronine, and thyroxine were determined at birth and at ages 3, 7, and 21 days. Nerve conduction velocity was measured in the first week of life, on day 21 , and at 40 weeks' postmenstrual age.

Seven infants maintained their thyroxine concentration above $60 \mathrm{nmol} / \mathrm{l}(4.67 \mu \mathrm{g} / 100 \mathrm{ml})$ throughout the study. Three of these infants needed mechanical ventilation and one had an intraventricular haemorrhage. Twenty six infants developed hypothyroxinaemia (thyroxine $<60$ $\mathrm{nmol} / \mathrm{l})$. The nerve conduction velocity was delayed in 13 infants, two on day 21 and 11 at 40 weeks' postmenstrual age. The delay was equivalent to 1.9-4.4 weeks. All these infants belonged to the group with depressed thyroxine concentrations. The delay in progression in nerve conduction velocity was associated with prolonged hypothyroxinaemia, especially in those infants who also required ventilation.

Further studies are in progress to study the effect of thyroid hormone on the nerve conduction velocity in preterm infants.

Low thyroxine concentrations are well documented in preterm infants, especially those who are less mature or have respiratory distress syndrome. ${ }^{12} \mathrm{~A}$ combination of low thyroxine concentrations with raised thyroid stimulating hormone concentrations has been reported in only one study and was due to a relative iodine deficiency. ${ }^{3}$ In all other reports low thyroxine concentrations have been associated with either normal or low thyroid stimulating hormone concentrations. It has therefore been assumed that low thyroxine concentrations are an expression either of immaturity or of a disturbance of the hypothalamic-pituitary-thyroid axis. ${ }^{4}$ Whether the disturbance is secondary to, or associated with, abnormal cerebral metabolism in association with the periventricular-intraventricular haemorrhage to which these infants are prone has so far not been documented. ${ }^{5}$

Low thyroxine concentrations normalise spontaneously over three to nine weeks. ${ }^{67}$ No consistent physiological disturbances have been noted in these immature infants, nor is it known whether these transient low thyroxine concentrations have a simi- lar harmful effect on the developing nervous system, as noted in children with prolonged hypothyroxinaemia due to congenital hypothyroidism. Delayed myelination has been observed in hypothyroidism, both in humans and animals. ${ }^{8}$ Slow nerve conduction velocity and immature visual evoked potentials have been reported in infants with congenital hypothyroidism and are believed to be an expression of the decreased peripheral and central myelin formation. ${ }^{9}{ }^{10}$ If the assumption can be made that abnormal thyroid function will also affect myelination in the premature infant then one would expect to find a slower postnatal maturation of nerve conduction velocity in infants with low thyroxine concentrations compared with those with normal thyroid function.

The aim of the present study was to assess neurological maturation as measured by nerve conduction velocity in premature infants with normal and abnormal thyroid function and to find out whether there is any relation between periventricular-intraventricular haemorrhage and abnormal thyroid function. 


\section{Patients and methods}

Thirty three very low birthweight infants, admitted to Hammersmith Hospital regional intensive care unit between February and September 1984, were enrolled in a longitudinal study. Informed parental consent was obtained in each case. All infants had a gestational age of 31 weeks or less and a birth weight of $1500 \mathrm{~g}$ or less. Gestational age was obtained from maternal dates, early prenatal ultrasound assessments when available, and clinical assessments according to the criteria of Dubowitz et al. ${ }^{11}$ Infants were only included if these initial examinations agreed to within one week.

Serial measurements of triiodothyronine, thyroxine, and thyroid stimulating hormone were taken on cord blood and on venous samples on days 3,7 , and 21. Samples were also obtained in seven children at 40 weeks' postmenstrual age.

Assays. Serum triiodothyronine, thyroxine, and thyroid stimulating hormone concentrations were measured by double antibody radioimmunoassay MRC, using MRC standard $68 / 38$ for the thyroid stimulating hormone assay. Normal ranges of thyroxine and triiodothyronine for adults are $70-150 \mathrm{nmol} / \mathrm{l}$ and $1-2 \cdot 8 \mathrm{nmol} / \mathrm{l}$, respectively. The samples were assayed in batches and the results unknown until after measurement of nerve conduction velocity had been performed at 40 weeks' postmenstrual age.

Nerve conduction velocity was calculated using combined velocities of the ulnar and posterior tibial nerves as described by Moosa and Dubowitz, ${ }^{12}$ using a Medelec MS 8 machine. This method has been shown to be reliable and can predict gestation with a standard deviation of 1.14 weeks. ${ }^{13}$ Nerve conduction velocity was measured in the first week of life, on day 21 , and as close as possible to 40 weeks' postmenstrual age (range 39-43 weeks).

Cranial ultrasound examinations were performed daily during the first week of life to diagnose and time the occurrence of periventricular-intraventricular haemorrhage. An ATL mechanical sector scanner was used.
Statistical analysis was determined by the Fisher's exact test.

\section{Results}

The infants were divided into two groups based on the thyroxine concentrations being consistently at or above $60 \mathrm{nmol} / \mathrm{l}(4.67 \mu \mathrm{g} / 100 \mathrm{ml})$ or below $60 \mathrm{nmol} / \mathrm{l}$ at any time during the study. This concentration is often taken as a cut off point for preterm infants in neonatal screening programmes. ${ }^{3}$

Group 1 (thyroxine $\geqslant 60 \mathrm{nmol} / \mathrm{l}$ ) consisted of seven infants and group 2 (thyroxine $<60 \mathrm{nmol} / \mathrm{l}$ ) of 26. Clinical findings of the two groups are summarised in the Table. The mean gestational age was 29.1 weeks (range 28-31) in group 1 and 28.6 (26-31) in group 2 . The infants in group 1 seemed less severely ill. Of the seven infants in group 1, two needed mechanical ventilation for respiratory distress syndrome and one for retained lung fluid, whereas in the second group 15 of the 26 infants needed ventilatory help, 12 for respiratory distress syndrome and three for apnoeic spells of immaturity.

Thyroid function. In the seven infants who maintained the thyroxine concentration above $60 \mathrm{nmol} / \mathrm{l}$ (group 1) a relative trough was seen on day 7 , with a pronounced rise on day 21 . Of the 26 infants who developed hypothyroxinaemia (thyroxine $<60$ nmol/l) (group 2), 12 infants reached a trough on day 3 and 14 on day 7 . In 18 of the 26 infants the thryoxine concentration was still below $60 \mathrm{nmol} / \mathrm{l}$ on day 21 , and the mean concentration on day 21 in group 2 was still low $(57 \mathrm{nmol} / \mathrm{l}(4.43 \mu \mathrm{g} / 100 \mathrm{ml}))$. In two of the seven infants, tested at 40 weeks' postmenstrual age, the thyroxine concentration was still below $70 \mathrm{nmol} / \mathrm{l}(5.44 \mu \mathrm{g} / 100 \mathrm{ml})$.

Triiodothyronine concentrations were found to be immeasurable $(<0.6 \mathrm{nmol} / \mathrm{l}(0.04 \mathrm{ng} / \mathrm{ml}))$ in 24 of our 33 infants during the first three days of life. Triiodothyronine concentrations were still below $0 \cdot 6$ $\mathrm{nmol} / \mathrm{l}$ on day 7 in 17 infants. Only one infant with a triiodothyronine concentration below $0.6 \mathrm{nmol} / \mathrm{l}$ on day 7 belonged to group 1 , the other 16 belonging to

Table Clinical findings in the two study groups

\begin{tabular}{lclll}
\hline Study group & $n=$ & $\begin{array}{l}\text { Gestational age (wks) } \\
\text { (mean (range)) }\end{array}$ & $\begin{array}{l}\text { Birth weight (g) } \\
\text { (mean (range)) }\end{array}$ & $\begin{array}{l}\text { Intermittent positive } \\
\text { pressure ventilation } \\
\text { intraventricular } \\
\text { haemorrhage }\end{array}$ \\
\hline Thyroxine $\geqslant 60 \mathrm{nmol} / \mathrm{l}$ & 7 & $29 \cdot 1(28-31)$ & 1035 \\
Thyroxine $<60 \mathrm{nmol} / \mathrm{l}$ & 26 & $28 \cdot 6(26-31)$ & $\begin{array}{l}(635-1350) \\
1107\end{array}$ & 15 \\
\hline
\end{tabular}

Conversion: SI to traditional units-Thyroxine: $1 \mathrm{nmol} / \simeq 0.078 \mu \mathrm{g} / 100 \mathrm{ml}$. 
group 2. Although the triiodothyronine concentrations tended to rise during the study in both groups, the mean concentration in group 2 was still low on day $21(0 \cdot 85 \mathrm{nmol} / 1(0.055 \mathrm{ng} / \mathrm{ml}))$.

Thyroid stimulating hormone concentrations remained below $20 \mathrm{mU} / 1$ in all infants throughout the study, but in three of these there was a raised concentration on one occasion only (on day 3 , range $10 \cdot 2-19 \cdot 8 \mathrm{mU} / \mathrm{l})$. All other thyroid stimulating hormone concentrations were normal (range $<1-7 \cdot 5$ $\mathrm{mU} / \mathrm{l})$.

Nerve conduction velocity. Normal postnatal acceleration of the nerve conduction velocity was found in 20 infants, while the velocity was delayed in 13 infants. In group 1 (with normal thyroxine concentrations) the nerve conduction velocity was normal on day 21 and at 40 weeks' postmenstrual age (Fig. $1(\mathrm{a}))$.

In group 2 (with one or more low thyroxine concentrations) the nerve conduction velocity was delayed in 13 of the 26 infants at 40 weeks' postmenstrual age. Two of these infants already showed a slow velocity at 21 days, whereas the remainder were normal at that stage. The other 11 showed a normal increase between the first and the third week of life and the delay was first noted at $\mathbf{4 0}$ weeks' postmenstrual age (Fig. 1(b)). The incidence of delay in nerve conduction velocity at 40 weeks' postmenstrual age, of 1.9 weeks or more, was significantly different between the two groups $(p<0.02$ by one tailed Fisher exact test).

Ten of the 13 infants with a delay in nerve conduction velocity had prolonged hypothyroxinaemia (low thyroxine concentrations on day 7 and 21) (Fig. 2). Nine of these 10 infants required ventilation. Eight further infants had prolonged hypothyroxinaemia but a normal nerve conduction velocity at 40 weeks' postmenstrual age, and only three of these infants were ventilated. A combination of ventilation and prolonged hypothyroxinaemia was thus present in nine of the 13 infants with a delay in nerve conduction velocity and in only three of the 13 with normal nerve conduction velocity $(\mathrm{p}<0.02)$.

No difference in the nutritional state at 40 weeks'

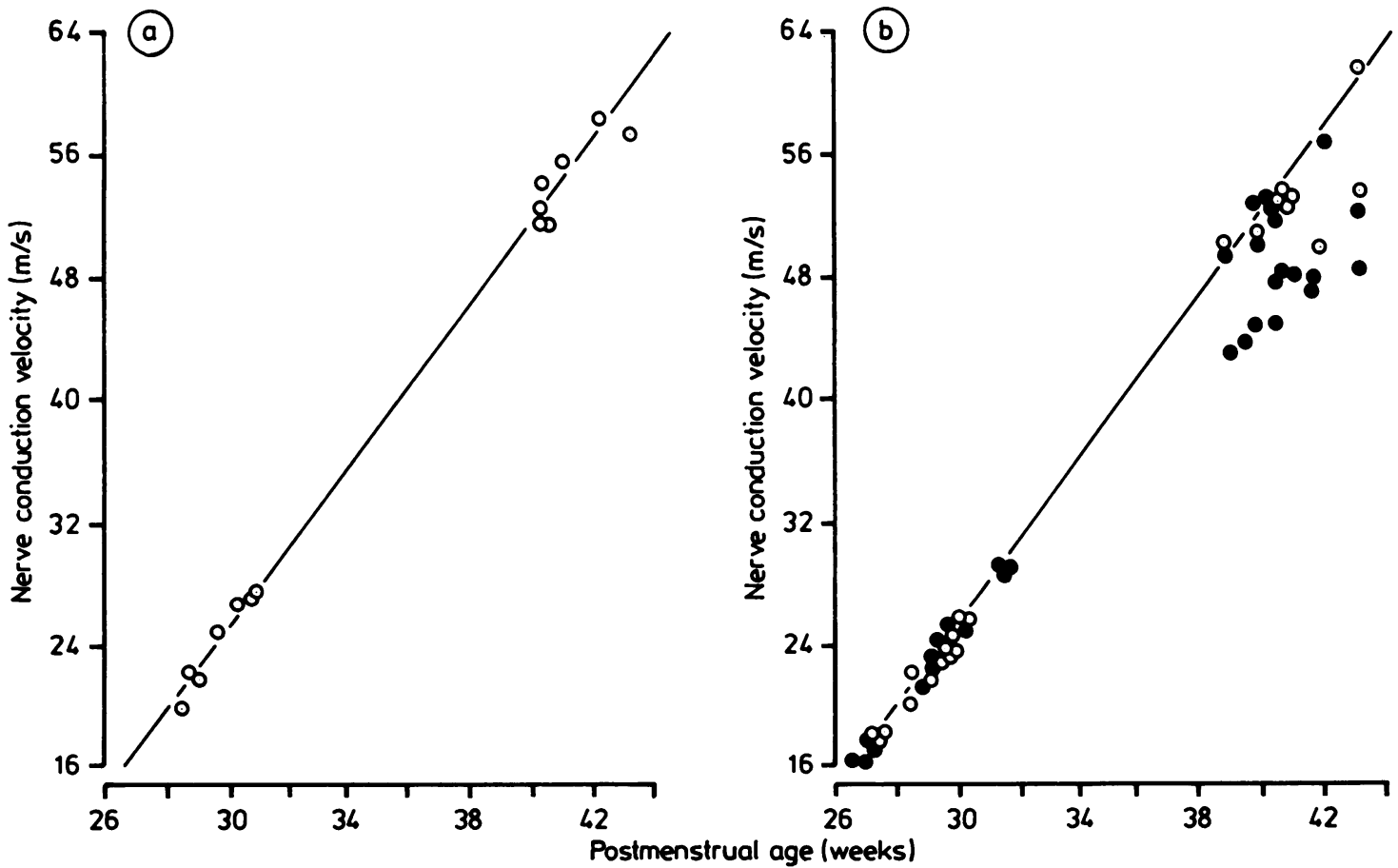

Fig. 1 Nerve conduction velocity during the first week of life (lower cluster) and at 40 weeks' postmentstrual age (39-43 weeks) (upper cluster) in infants with (a) thyroxine $\geqslant 60$ nmol/l and (b) thyroxine $<60$ nmolll $(\bigcirc=$ thyroxine $<60$ nmolll on one occasion (day 3 or 7$) ; 0=$ thyroxine $<60$ nmolll on two occasions (day 7 and 21)). 


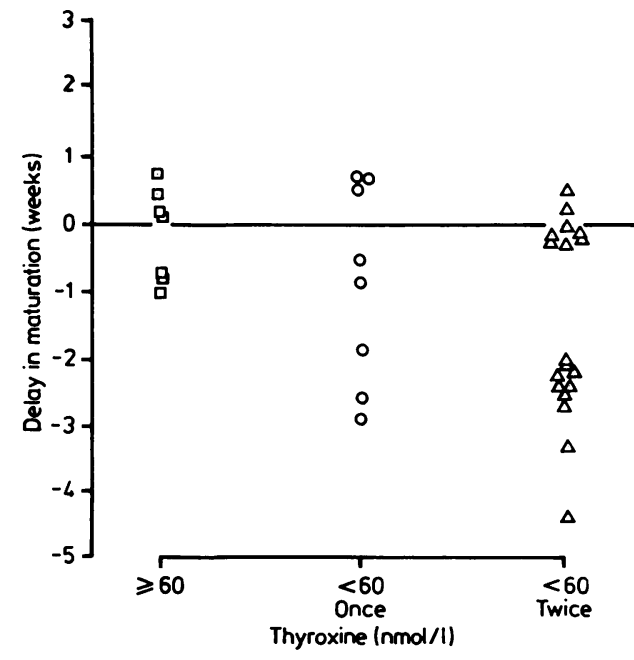

Fig. 2 Progression in nerve conduction velocity between birth and 40 weeks' postmenstrual age in infants with a thyroxine concentration $\geqslant 60,<60$ on one occasion (day 3 or 7), and $<60$ nmolll on two occasions (day 7 and 21).

Conversion: SI to traditional units-Thyroxine: $1 \mathrm{nmol} / \approx 0.078 \mu \mathrm{g} / 100 \mathrm{ml}$.

postmenstrual age in terms of overall weight gain could be found between infants with and without the delay in nerve conduction velocity.

Ultrasound findings. Sixteen infants developed a periventricular-intraventricular haemorrhage. A haemorrhage was noted in 15 of the 26 infants with low thyroxine concentrations compared with one of seven with normal thyroxine concentrations. $(\mathrm{p}<0 \cdot 05)$.

\section{Discussion}

Our findings support previous observations that prematurity and severe illness are associated with a disturbance of the thyroid axis and thus with hypothyroxinaemia in the absence of increased thyroid stimulating hormone concentrations. Twenty six $(78 \%)$ of our patients developed thyroxine concentrations below $60 \mathrm{nmol} / \mathrm{l}$ and 21 $(65 \%)$ still had concentrations below $60 \mathrm{nmol} / \mathrm{l}$ at 3 weeks of age. The high incidence of hypothyroxinaemia and the slow recovery rate in this study, compared with other studies ${ }^{6}{ }^{6}$ are most likely due to the immaturity of our population.

The high incidence of periventricular-intraventricular haemorrhage in the population might be another important associated factor in the hypothalamic disturbance. Fifteen of the 26 infants with low thyroxine concentrations had an associated haemorrhage compared with only one of seven with normal concentrations. It is noteworthy, however, that in six infants low thyroxine concentrations were already present before the bleed could be visualised by ultrasonography and no correlation could be found between the size of the bleed and the degree of the endocrine disturbance. It is thus possible that the hypothalamus is not directly affected by the haemorrhage itself but by the circulatory disturbance leading to it.

This study also shows that the hypothyroxinaemia may be prolonged beyond the first two to three weeks of life. This is supported by the results of Chowdry, who studied a comparable population and only found stabilisation of serum thyroxine between 7 and 9 weeks postnatally. ${ }^{7}$ Only seven of our infants could be tested at 40 weeks' postmenstrual age, and two still had a thyroxine concentration below $70 \mathrm{nmol} / \mathrm{l}$. Unfortunately, we were unable to document the exact duration of the hypothyroxinaemia in most of our infants as most of them were referred back to the referring hospital shortly after the end of the study.

This study also shows an association between thyroxine concentrations and nerve conduction velocity. Normal maturation was found in all infants with normal thyroxine concentrations, whereas 13 of the 26 infants with low concentrations had a delayed maturation. The nerve conduction velocity seemed to be more often delayed in those infants who still had thyroxine concentrations below $60 \mathrm{nmol} / \mathrm{l}$ on day 21. A number of infants, however, had a normal nerve conduction velocity at 40 weeks' postmenstrual age in spite of prolonged hypothyroxinaemia. While most of the infants with prolonged hypothyroxinaemia and a delay in nerve conduction velocity were preterm infants who required ventilation, most of the infants with prolonged hypothyroxinaemia and a normal nerve conduction velocity were healthy. Thus it is possible that slow nerve conduction velocity may be caused by a third unmeasured factor associated with illness. An effect of nutrition on growth and myelination cannot be excluded, but the similar weight gain at 40 weeks' postmenstrual age of the infants with and without delayed nerve conduction velocity makes this unlikely.

There is an established association with hypothyroidism and delayed maturation in congenital hypothyroidism and in hypothyroidism in adults. ${ }^{914}$ Two explanations have been given in these studies for the delayed nerve conduction velocity-delay in myelination and disturbance in the neurotransmitter mechanism. ${ }^{15}$

Previously, there has been no biological evidence that transient hypothyroxinaemia associated with prematurity is harmful, but the question whether 
treatment is indicated is often raised..$^{16}$ These results suggest that transient hypothyroxinaemia may interfere with neurological maturation, as shown by delay in maturation of nerve conduction velocity, and raise the question whether treatment of hypothyroxinaemia may influence the maturation of nerve conduction velocity. Two studies have been reported where treatment for hypothyroxinaemia was given. In one prophylactic treatment with triiodothyronine or thyroxine was used in all preterm infants less than 37 weeks' gestation or below $2200 \mathrm{~g}$, or both, with a fourfold reduction in the mortality in the treated group. ${ }^{17}$ In the other study thyroxine was selectively administered for treatment of preterm infants between 25 and 28 weeks' gestation with two or more thyroxine concentrations below 60 nmol/l. ${ }^{7}$ The outcome between the treated and non-treated group was not different, but only eight of the 23 infants were seen at follow up. Although the increase in thyroxine concentrations was not different between the two groups, no triiodothyronine concentrations were reported and an increased conversion of thyroxine into triiodothyronine cannot therefore be excluded.

Our aim in the present study was to establish a method that would enable us to measure on a short term basis the biological effect of thyroid function. We were able to show an association between disturbed thyroid function and delay in nerve conduction velocity. Whether this delay is mainly influenced by thyroxine concentrations can best be evaluated by the effect of treatment of hypothyroxinaemia on nerve conduction velocities, and such a prospective study is currently in progress in our unit.

We thank Professor M J R Healy (Professor of Medical Statistics) and Professor J L van den Brande (Professor in Paediatric Endocrinology) for help and advice and Mr M C Sood for technical help.

Dr de Vries was supported by a grant from the National Fund for Research into Crippling Diseases (Action Research for the Crippled Child) and Dr L M S Dubowitz by a grant from the Medical Research Council.

\section{References}

${ }^{1}$ Klein AH, Foley B, MacDonald HM, Fisher DA. Thyroid studies in cord blood from premature infants with and without RDS. J Pediatr 1981;98:818-20.

2 Uhrmann S, Marks KH, Maisels MJ. Thyroid function in the preterm infant: a longitudinal study. $J$ Pediatr 1978;92:968-73.

${ }^{3}$ Delange F, Dalhem A, Bourdoux P, et al. Increased risk of primary hypothyroidism in preterm infants. $J$ Pediatr 1984;105:462-9.

${ }^{4}$ Hadeed AJ, Asay LD, Klein AH, Fisher DA. Significance of transient postnatal hypothyroxinaemia in preterm infants with and without respiratory distress. Pediatrics 1981;68:494-8.

${ }^{5}$ Levene MI, Fawer C-L, Lamont R. Risk factors in the development of IVH in the preterm neonate. Arch Dis Child 1982;57:410-7.

${ }^{6}$ Uhrmann S, Marks KH, Maisels MJ, Kulin HE, Kaplan M, Utiger R. Frequency of transient hypothyroxinaemia in low birthweight infants. Arch Dis Child 1981;56:214-7.

${ }^{7}$ Chowdry P, Scanlon JW, Auerbach R, Abassi V. Results of a controlled double blind study of thyroid replacement in VLBW infants with hypothyroxinaemia. Pediatrics 1984;73:301-5.

${ }^{8}$ Bas NH, Young E. Effects of hypothyroidism on the differentiation of neurons and glia in the rat cerebrum. J Neurol Sci 1973;18:155-73.

${ }^{9}$ Moosa A, Dubowitz V. Slow nerve conduction velocity in cretins. Arch Dis Child 1971;46:852-4.

${ }^{10}$ Hrbek A, Fallstrom SP, Karlberg P, Olsson T. Clinical application of evoked EEG responses in infants III: congenital hypothyroidism. Dev Med Child Neurol 1982;24:164-72.

11 Dubowitz LMS, Dubowitz V, Goldberg C. Clinical assessment of gestational age in the newborn infant. J Pediatr 1970;77:1-10.

12 Moosa A, Dubowitz V. Assessment of gestational age in newborn infants: nerve conduction velocity versus maturity score. Dev Med Child Neurol 1972;14:290-5.

${ }^{13}$ Miller G, Heckmatt JZ, Dubowitz LMS, Dubowitz V. Use of nerve conduction velocity to determine gestational age in infants at risk and in very low birthweight infants. $J$ Pediatr 1983;103:109-12.

14 Abbott RJ, O'Malley BP, Barnett DB, Timson L, Rosenthal FD. Central and peripheral nerve conduction in thyroid dysfunction: the influence of $\mathrm{L}$-thyroxine therapy compared with warming up on the conduction abnormalities of primary hypothyroidism. Clin Sci 1983;64:617-22.

15 Bradley BP, Eayrs JT, Glass A, Hearh RW. The maturational and metabolic consequences of neonatal thyroidectomy upon the recruiting response in the rat. Electroencephalogr Clin Neurophysiol 1961;13:577-86.

16 Soulioti AMA, Al Roomi L. Transient neonatal hypothyroidism in very low birthweight infants: is treatment necessary? Lancet 1985;ii:493-4.

17 Schonberger W, Grimm W, Emmerich P. Reduction of mortality rate in premature infants by substitution of thyroid hormones. Eur J Pediatr 1981;135:51.

Correspondence to Professor V Dubowitz, Department of Paediatrics and Neonatal Medicine, Hammersmith Hospital, Du Cane Road, London W12 0HS.

Received 28 May 1986 